\title{
Way to Go: Mirroring Real Experiences of the Escape Rooms
}

\author{
Lim Qian Pink, Mohd Ridzuan Darun, Gusman Nawanir, Chiam Kee Swan
}

\begin{abstract}
Over the last decade, escape rooms have taken the entertainment industry by storm. Contenders sign up willingly, to be virtually locked up in unfamiliar rooms, with the understanding that they are in for an adventure of unravelling clues, puzzles and riddles as the clock ticks on them. While this phenomenon takes entertainment to the next level, the presence of escape rooms is extremely challenging in terms of continually catering to the appetites of a varied customer base. There are existing frameworks which touch on customer services, but unfortunately, none on this trade, which in fact, requires a lot of attention to ensure continuous growth and long term sustainability. This paper is an effort made to review our customers' experiences in our escape rooms in Malaysia, to determine the constructs that are fundamental to enhancing customer experience in escape rooms in Malaysia. In addition, it functions to improve and design games suitable to their needs and most important for their frequent comebacks. This research was carried out in two establishments situated in Klang Valley, Malaysia. There were twenty contenders and they have met the criteria of at least a one-time involvement in the game. The study is qualitative in nature and it is advocated by using the sequential incident technique to excavate the customers' perceptions which could be the base of our future Malaysian escape games. The analysis utilized is thematic and the results unearthed fifteen determinants in which nine are closely mirrored to the goaldirected behaviour model. The research benefits the discipline of customer experience mapping in this unique industry and the future escape room designs and enhancement for our escape rooms' entrepreneurs.
\end{abstract}

Keywords: Customer experience, escape room, sequential incident technique, goal-directed behavior.

\section{INTRODUCTION}

The number one purpose of any business is to serve its customers failure of which practically ensures its imminent doom. That is why, in [1] professed that excavating customers' experiences is a vital necessity in the development and management of all industries. In fact, at this turn of century, with technology and its revolution, many businesses are dependent on consumption behaviour. Hence, as in [2] said many have pursued research in this said customers' experiences tirelessly to prioritize their needs so that their businesses are jazzed to grow.

As a norm, customers are difficult to satisfy, as their needs and fancies often change. They are constantly gamed for something new; something more innovative. In [3] remarked that consumers are continually looking for experiences; fresh but exceptionally relatable and

Revised Manuscript Received on September 14, 2019.

Lim Qian Pink, Faculty of Industrial Management, Universiti Malaysia Pahang, Kuantan, Malaysia. (Email: qianpink87@gmail.com)

Mohd Ridzuan Darun, Faculty of Industrial Management, Universiti Malaysia Pahang, Kuantan, Malaysia. (Email: mriduzand@ump.edu.my)

Gusman Nawanir, Faculty of Industrial Management, Universiti Malaysia Pahang, Kuantan, Malaysia. (Email: gusman@ump.edu.my)

Chiam Kee Swan, Centre of Modern Languages, Universiti Malaysia Pahang, Kuantan, Malaysia. (Email: chiam@ump.edu.my) memorable ones.

Many researchers understand customers' experiences is paramount to businesses so they have worked and constructed an array of conceptional frameworks in business management to ensure knowledge in this field is well equipped [4]-[6]. Nevertheless, in this new and innovative business, the escape room industry which is categorized under entertainment has substantial gaps to explore. Past indepth studies are mainly on traditional services such as retail and banking industries. In [7] commented that when it comes to tourism, traditional tourism has its fair share of research findings but these new-fangled modernized attractions - sometimes known as game induced tourism or urban tourism such as escape rooms are generally unexplored territory.

In [8] said there should more studies to ensure proper growth in this particular unique niche on the basis that it is human nature to want to feel smart. Hence, it is perfect, as escape rooms do not indulge in dangerous and lifethreatening risks like sky diving or bungee jumping. The rush of adrenaline of solving puzzles in hope to escape a simulated danger before time does run out is just as appealing and challenging.

Escape room games are synonymous as live action computer games where in [9] said players (friends, families and colleagues) are teamed up to find the right clues and solve puzzles within a stipulated time to overcome the made belief disaster or escape the created scenario. Originating from Japan, back in 2007, these reality games are top notch nightmare games and the most loved ones simulate hijacked airplanes, derailed subway cars and trapped submarines. In [10] mentioned that these said games are well received in the United States for the past years and it is a growing trade since 2014. To date, escape room games are now in its hype in all the major cities of Asia and Europe.

There are roughly 4000 establishments of escape rooms in well over 90 countries worldwide. As a young industry, it exhibits steady growth each year [11]. In [12] reported successful escape rooms have the ability to gain profits from their initial capital after a mere five months of operation and subsequently enjoy $800 \%$ sales growth annually.

Today, escape rooms have found fertile soil in Malaysia. Malaysia is deemed number two in number of establishments in the whole of Southeast Asia owing to the mushrooming growth in number of establishments over the last few years. There are a total of twenty-three establishments in Malaysia of which three are globally recognized. The first in line was established in 2013 by Escape Room Holdings in the heart of Kuala Lumpur and it 
was money-spinning as Malaysians are inclined to this innovative interactive play. According to Asian Entrepreneur in 2016, in no time, Malaysia have produced some renowned "home grown" escape rooms themes which have found their way into various countries such as Canada, United States, South Korea and Myanmar. Its wide range of franchise was the credit points of its award as the Asian Entrepreneur of the Year. In fact, in [13] has mentioned that there is one legally registered company in Malaysia which is now rich and famous in the entertainment sector due to its accumulated net asset of RM1.45 million and an amazing net profit of RM1.03 million.

In [10], on the other hand, argued that, this pot of gold is not as sustainable as it seems. Entrepreneurs, on the long run, face a huge challenge on making and keeping a significant customer base enough to attain lucrative profits over an extended period of time. In [14] has earlier proclaimed that there is little chance for the customers to reexperience the game set, once they have successfully completed it. This is basically because as thrilling and exciting the game was the first time around, the novelty of the experience is lost soon after. If a player plays a second time, it is probably to share their joy with others who have yet to play; where many a times, they are being hushed down for dropping unnecessary hints.

Hitherto, there are no substantial studies conducted on this industry to keep its booming success intact or before it turns downhill. There are only two available search results; one whitepaper and one academic journal published [9], [15].

In [9] did a global survey of 175 proprietors in various countries and has only done the basic i.e. an overview of the players' demographic characteristics, the various structures of the escape rooms which include the different themes, storylines, clues and hodge-podge puzzles. There is none related to the insights of customers' experiences which are of utmost importance to the trade. In fact, their preferences should be noted down to further enhance the games.

In [15], on the other hand, made an effort to conceptualize experiences of the games played in the escape rooms through Trip Advisor reviews by its customers on certain escape rooms found in the United States and Europe. Ostensibly, he has used netnography and the automated research analysis for his study which is empirical to the western countries. His findings are based on customers' revelations. They are of strong and positive emotions during gameplay in which he linked those founded experiences to what is known as perceived authenticity and flow.

Given the fact that there is an absence of extensive studies on our customers' reflection of experiences, our proprietors are in the endangered zone to the extinction of an exclusive source of entertainment which is perfectly healthy and profitable. Hence, this study is set to do the inevitable; first to discuss the theoretical framework of customers experiences and second, to explore the crucial points that are inter-related to the conceptualization of the said experiences; the way to go in mirroring real life experiences of our escape rooms.

\section{LITERATURE REVIEW}

\section{A. The Roots of Customer Experience and its Developments}

Long-term success of any business organization is pivoted on customer experience. Existing literature dated way back in the 80 s have proven its net worth as a core priority. As in [16] mentioned customer experience is basically derived from the studies of human psychology and consumers' behaviours towards consumption. However, human consumption is often thought as a black hole as it is difficult to quantify. Hence, researchers have concluded to conceptualize this amazing factor (human consumption) on an abstract level right from the beginning.

In [17] probed the limits of human identity and proclaimed them as creatures of unrestricted degree of freedom with strong peripheral beliefs. In [16] agreed with this school of thoughts and did a challenge on the conventional information processing model which states men as rational decision makers. They proposed the experiential aspects of consumption which has elements of symbolism, hedonism, and estheticism such as consumer fantasies, feelings, and fun. Prior to this, there is another belief which relates human behavioural responses specifically their basic emotions of pleasure, dominance and arousal to environmental stimulation [18].

The conceptual frameworks are durable in their own sense. Further researchers then applied these said frameworks to service design and marketing. Hence, today we have concepts from researchers like service-scape [19] and experiential marketing [20].

In the 90's, the concentration of research was basically to look for the right customer experience model. Its difficulty arises as mentioned before is due to its abstract nature. However, there is emergence of a new concept which is named flow experience [21].

Flow experience is referred to as a mental affair whereby immersion takes place and is simultaneously triggered when the perfect environment is attained and well induced. This is, in fact, a very subjective experience. One is said to be living in the flow, when there is a loss of consciousness over time and work is at full capacity. In simple words, it is the operational zone of one's mental state in which one conducts a certain activity with full enthusiasm, immensely energized with complete focus and filled with great enjoyment [22].

In [23] talked of the magic consumption. They addressed the commercial dimension in terms of interactive exchanges; the interaction of the promoter (products) and customer. As said, commerce has the ability to deliver authentic experience and it initiates a much greater satisfaction to the customer who in turn attains positive emotional outcomes as well.

Subsequently, there is an addition of a vital condition and that is to ensure these experiences are made as memorable as possible for customers to be hooked on their feelings. Such a wise action is, in fact, no other than a pre-condition 
to accomplish effective branding in modern marketing [24].

Nevertheless, in single moment experiences, in [25] beg to differ. Here, the encounter of customer experience need not be specifically exclusive each and every single time around. In fact, it should be self-manifested accordingly to the happenstance of intensity levels which are basically hinged on the context of where the interaction occurs [25].

This school of thought is well received by [26] who constructed a theoretical framework of service dominant logic which cordially inscribed the value of offering being perpetually dependent on the fundamentals of service and applicable experiences.

To date, researchers are on to sustainability of the creation of customer experience. In [27] embraced the stand in which all businesses; be it of services or trades, ought to fully investigate the nooks and corners of customer experience in detail to attain a successful business strategy. In their explanation, they stressed the importance of understanding the value of customer experience at the various stages as it is a vibrant journey that potentially aids the crafting of right clues in which will then act as a proper guidance to the customer purchase experience.

In [28] agreed heartily as they are firm believers of customer experience being the core agent to reduce churn and increase revenues of any organizations. In [29] then added, customer experience, hypothetically, is also deemed to be affected by customers' past experiences and hence it check-balances the delivery of services and satisfactory levels efficiently and effectively.

Nowadays, there are more and more collaboration of companies and their customers as they are set to meet the fast-changing customer demands. This is feasible as they are now able to closely analyse the customer experience [30], [31]. Hence, there exists innovation solutions where customers' purchase experience is enhanced tremendously i.e. from improved customer engagements to advanced technology enhancement which includes delivery in terms of utilizing technology to initiate self-services [3], [32] customer care services [33], [34] and also big data analytics [35] in this wonderful world of internet.

In conclusion, customer experience is summarized as one of the most complex multi-dimensional structures to be explored. Its timeline is indefinite and extremely subjected to the context of interaction of the business and its customers. Hypothetically, the better experience customers have, the more successful the business flourishes. Thus, it is vital to imperatively understand what captures the heart of the customers and decipher how to net catch them. It is also best to address their expectations to have repeated custom and attain positive reviews. In the escape room business organizations, customer experience is, in fact, the key differentiator and driver for its growth and sustenance. This is due to the fact that, they sell experiences. The experience is escape, both in the literal and metaphorical sense and it is pertinent for their game plans to be suited to their customers who seek this sort of adventure. In spite of it all, no significant research is conducted extensively to secure the future of this niche of entertainment.

\section{B. The Model of Goal-Directed Behaviour (MGB)}

The Model of Goal directed Behaviour (MGB) is the extension of the Theory of Planned Behaviour introduced by [36]. This model has considerations made for behavioural acts in its quest of pursuing further goals

MGB is endeavored to excavate in depth and widen the base Theory of Planned Behaviour (TPB) and the Theory Reasoned Action (TRA) accordingly. The newly introduced areas are of the affect, motivation and habit which explain the defining roles of (1) desire in determining any behavioural intentions, (2) anticipated emotions; positively and negatively as decision- making occurs and (3) on past and frequency behaviours affecting its behavioural intention. The model is said to deliver a much higher performance in comparison to TPB in its predictive utility [37].

Interestingly, MGB categorizes attitude, subjective norm, perceived behavioural control and anticipated emotions as indirect affect behavioural intention channeled through desires [36], [38], [39]. The importance of anticipated affective reactions of behaviour is the core structure of MGB. These anticipated affective reactions to the performance or non-performance of a behavior, are selfregulated. Emotions are implied in its assessment of success or failure in the process of decision making [40] predominantly when high uncertainty transpires [41], [42]. In [43] then concluded with reference to past behaviours, the ability to predict behaviour is feasible as they are used to proximate habits.

Initially, MGB research is aimed to understand humans and their addictive behaviours such as the crazy obsessions on drugs use [44], [45] and alcohol consumption [46]. Research has proven that there is strong correlation of anticipated emotions and other TPB elements in attaining desire.

Consecutively, MBG is applied into management studies to understand revisit intentions in the tourism industry. In [47] undertook such a research on 423 visitors of the Sancheong Herbal Festival in South Korea. They surveyed on their attitudes, subjective norm, and anticipated emotion and concluded these elements influenced visitors' desire to attend the festival, and its influence on their behavioural intentions. Another such study is by [48] who investigated the propensity for residents and non-residents to visit the Iowa wetlands recreational park. The results displayed residents who have positive attitude towards Iowa wetlands are bound to frequently visit as they have much stronger desire to revisit as opposed to non-residents of the said area.

Looking at the nature of MGB, this model is extremely suitable for the study of escape rooms management. MGB has potential in solving the challenges faced by this new entertainment industry. With good analysis of its customer experience, escape room operators are able to create or innovate their products i.e. the structure of their gameplay. On the other hand, they will have a better chance of retaining a reliable customer base and perhaps even revisits regularly in the near future. Ultimately, to keep this industry sustainable, it is vital to decrypt customers' minds and design cost effective escape rooms suited to customers' fancies and whims. MGB is able to provide these guidelines 


\section{WAY TO GO: MIRRORING REAL EXPERIENCES OF THE ESCAPE ROOMS}

hence this study is warranted.

\section{METHODOLOGY}

The utilization of customer experience in this study is to attain holistic perception of the customers on their experiences with these escape rooms entertainment. The more in-depth the customers' thoughts and perspectives, the better gameplays are being produced.

In this paper, the study engaged the sequential incident technique and used a qualitative research approach to construct holistic knowledge on the matter through a comprehensive assessment of customers' reflection collected. In [49] stressed that these said methods are commonly applied to study customer experience. Other researchers admitted they have broadly been used in service marketing [50], [51] and operations management [52].

\section{A. Sample Selection}

This study employed a purposive sampling, as the nonprobability samples were required to have certain characteristics of a population. In [53] said this is basically to ensure the information gathered well-represents the informants. In addition, the objectives of the study need to be met. In [54] declared it is the researchers' job to attain information-rich cases regardless how limited the resources may be.

The criterion for participation in this study was that informants must have played at least once in any of the escape rooms available in Malaysia. As such, samples were gathered with permission granted by two relatively renowned escape room operators. The informants were interviewed straight after their gameplay to gain fresh insights.

\section{B. Data Collection}

As mentioned earlier, data collection was through an immediate interview after the gameplay. The sequential incident technique (SIT) was employed to extract collective incidents of the whole process of the gameplay from the informants [55].

This SIT approach is sourced from the critical incident technique (CIT) in which in [56] describe as having processes set specifically to gather human behavior directly, which incidentally promotes prospective utilization to resolve practical issues and develop wide psychological values. In [57] then continued, its storytelling technique has given room for many researchers to figure out distinctive phenomenon and at the same time, appreciate non-critical incidents when significant themes are being identified along the way. The subjects are given full freedom to speak of their experiences and they use their own words in their descriptions of their purchase journey; pre-purchase, purchase and post purchase consecutively with guidance. In the context of this study, subjects were being questioned on their first impressions of escape rooms (pre-purchase), their experience during gameplay (purchase) and their feelings after completion (post-purchase).

Earlier, a search of related literature was conducted on customer experience which includes synonymous terms such as service experience and consumption experience to establish the framework of study based on the key word "experience". During the interviews, subjects answered open-ended questions in which they contribute their thoughts, words and deeds; as much information as they wished to expose, and the researcher had the liberty to further question; a follow-up technique to attain more details based on what have been said in the process [58]. In [59] commented that all open-ended questions posed should be worded clearly, in a concise manner and crafted with a neutral tone so that it is interviewer bias free. Hence, the questions of this study were vetted by marketing experts and pre-tested with a sample of interviewees to ensure its validity. All technical jargons related to customer experience were avoided as in [54] said it is for the best, as there have been many reported cases of confusion.

During the first interview with a group of pairs, the researcher asked each of them to explain briefly what they thought of the gameplay they had experienced in the escape room from the pre-purchase stage to the post purchase stage.

The two subjects, as first timers were more than excited to talk about what they had encountered in detail. They not only described their experience, but they touched on what they were asked to do to proceed the escape until the end. They completed the gameplay in the set time.

Based on the SIT technique, the said subjects were then asked to recall distinctive episodes to the best of their abilities. They did well especially the one who found the hidden clues and solved most the puzzles. They gave a full description in their own words without much prompts.

The researcher did question on their level of familiarity of the escape room gaming concept and found the majority are still "green" as they have just got into this real-life adventure game. In [60] said subjects should be thrown with more in-depth questions to attain better insights of their involvement so that data collected is diversified.

The second and third groups of subjects did not manage to complete their mission and escape the room. Another completed with the help of the gamemaster, while two others did not despite the guidance of the gamemasters. The researcher classified the subjects into four different categories as shown in Table I.

Table- I: Status score of subjects at end of gameplay

\begin{tabular}{|c|l|}
\hline Group & \multicolumn{1}{|c|}{ Descriptions } \\
\hline 1 & successfully escape room within the stipulated time \\
\hline 2 & $\begin{array}{l}\text { successfully escape room within the stipulated time with } \\
\text { guidance (gamemaster) }\end{array}$ \\
\hline 3 & failed to escape room within the stipulated time \\
\hline 4 & $\begin{array}{l}\text { failed to escape room within the stipulated time with guidance } \\
\text { (gamemaster) }\end{array}$ \\
\hline
\end{tabular}

Each category of subjects went through the same process as mentioned above. They were being asked further questions based on their responses. The only difference was after the first group of pair, the researcher recruited three more interviewers so that the interviews are individualized and could be conducted concurrently. This was implemented because the researcher felt there was a dominant speaker among the two. The later had chorus answers like, "yes, 
yes..." or "like what he said..." and "he is correct or even nodding head in agreement". Table II shows the demographic profile distribution of the respondents to this study.

Table- II: Demographic profile of respondents in two establishments of escape rooms

\begin{tabular}{|c|c|c|c|c|c|c|}
\hline $\mathbf{E}^{*}$ & GR* & $\mathbf{R}^{*}$ & $\mathrm{G}^{*}$ & Age & $\begin{array}{c}\text { Player } \\
\text { Type }\end{array}$ & Relationship \\
\hline \multirow[t]{9}{*}{ E1 } & \multirow[t]{2}{*}{1} & R1 & $\mathrm{M}$ & 21 & FP & Friends \\
\hline & & R2 & $\bar{M}$ & 21 & FP & Friends \\
\hline & \multirow[t]{3}{*}{2} & R3 & $\mathrm{F}$ & 35 & FP & Colleague \\
\hline & & R4 & $\mathrm{F}$ & 33 & RP & Colleague \\
\hline & & R5 & $\mathrm{F}$ & 31 & FP & Colleague \\
\hline & \multirow[t]{2}{*}{3} & R6 & $\mathrm{M}$ & 19 & FP & Friends \\
\hline & & R7 & $\mathrm{F}$ & 22 & FP & Friends \\
\hline & \multirow[t]{2}{*}{4} & $\mathrm{R} 8$ & $\mathrm{M}$ & 55 & FP & Family \\
\hline & & R9 & $\mathrm{F}$ & 45 & FP & Family \\
\hline & \multicolumn{6}{|l|}{1} \\
\hline & \multirow[t]{5}{*}{2} & $\mathrm{R} 10$ & $\mathrm{~F}$ & 22 & RP & Colleague \\
\hline & & R11 & $\mathrm{F}$ & 23 & FP & Colleague \\
\hline & & $\mathrm{R} 12$ & $\mathrm{~F}$ & 22 & FP & Colleague \\
\hline & & $\mathrm{R} 13$ & $\mathrm{M}$ & 16 & FP & Friends \\
\hline & & R14 & $\mathrm{M}$ & 17 & FP & Friends \\
\hline & \multirow[t]{3}{*}{3} & $\mathrm{R} 15$ & $\mathrm{~F}$ & 23 & FP & Colleague \\
\hline & & R16 & $\mathrm{M}$ & 25 & FP & Colleague \\
\hline & & R17 & $\mathrm{F}$ & 19 & FP & Independent \\
\hline & \multirow[t]{3}{*}{4} & $\mathrm{R} 18$ & M & 14 & FP & Family \\
\hline & & R19 & $\mathrm{M}$ & 16 & RP & Family \\
\hline & & $\mathrm{R} 20$ & $\mathrm{M}$ & 12 & FP & Family \\
\hline
\end{tabular}

*E refers to the establishment, GR is the group as defined in Table I, R is the respondent, $\mathrm{G}$ is gender where $\mathrm{M}$ is male and $\mathrm{F}$ is female.

To ensure, data collected is standardized, the researcher had a call back session with the pair. This was possible because the subjects were contactable through e-mail and they were willing to accommodate.

In total 30 narratives were extracted from the 20 semistructured interviews conducted in two establishments. The exit point of interview is at 15 th respondent when themes gathered kept repeating and there were no new developments to contribute to the data. In [61] said in post cross-case analysis, this happens when it hits the point of saturation. The researcher did another five cases to be certain, nothing was a miss. Interview sessions were run at an average of thirty-five minutes.

\section{Data Analysis}

All interviews were recorded and transcribed via OtterAi; a free audio transcribing software. Once the copies were ready, they were emailed to the respective subjects for accuracy check purposes. After verification and corrections (as per required), the transcripts were imported and analyzed using Nvivo software version 11.

Critical incidents were identified through this inductive approach where their transliterated responses were analyzed in-depth. Critical incidents referred to any antecedents and outcomes which are well described by the subjects. Any ambiguity in their statements (descriptions) would be discarded and removed from the data analysis as such were considered insignificant. This is a core step to safeguard data credibility after extraction [56] and it is vital, as these said incidents would be set to frame customer experience of the Escape Room for this study.

Subsequently, the emerging themes from the data were thoroughly studied through a cross-case analysis. The purpose was to detect the frequency of repeated themes among the 20 sample subjects. These constant appearing themes were then refined via a comparison to works of scholastic values to ensure terms used are correct and just; corresponding to past literature reviews. This stage of work was meant to achieve theoretical validity [62].

Two independent coders reviewed the extracted themes. They accessed the voice recordings interviews and made comparison to the data collected in the earlier assessment. This is aimed to enhance reliability of the said analysis.

The exercise potentially listed down 14 themes which coincide with earlier writings or published articles in journals. Table III showed the operational definition of each named theme.

Table- III: Demographic profile of respondents in two establishments of escape rooms

\begin{tabular}{|c|c|c|}
\hline No. & Themes & Operational Definition \\
\hline 1 & Attitude & $\begin{array}{l}\text { The degree to which an individual has a } \\
\text { favourable/unfavourable evaluation of } \\
\text { performing a specific behaviour. }\end{array}$ \\
\hline 2 & $\begin{array}{l}\text { Subjective } \\
\text { Norm }\end{array}$ & $\begin{array}{l}\text { The perceived social pressure to perform or not } \\
\text { to perform the behaviour. }\end{array}$ \\
\hline 3 & $\begin{array}{l}\text { Positive } \\
\text { Anticipated } \\
\text { Emotion } \\
\end{array}$ & $\begin{array}{l}\text { Positive affective appraisal arising from } \\
\text { subjective evaluation of an individual on the } \\
\text { likelihood to achieve intended outcome. }\end{array}$ \\
\hline 4 & $\begin{array}{l}\text { Negative } \\
\text { Anticipated } \\
\text { Emotion }\end{array}$ & $\begin{array}{l}\text { Negative affective appraisal arising from } \\
\text { subjective evaluation of an individual on the } \\
\text { likelihood to achieve intended outcome. }\end{array}$ \\
\hline 5 & $\begin{array}{l}\text { Perceived } \\
\text { Control } \\
\text { Behaviour }\end{array}$ & $\begin{array}{l}\text { Individual's perception of the ease or difficulty } \\
\text { in achieving intended outcome. }\end{array}$ \\
\hline 6 & Desire & $\begin{array}{l}\text { Degree of compulsion which drives a person to } \\
\text { action. }\end{array}$ \\
\hline 7 & $\begin{array}{l}\text { Frequency of } \\
\text { Past Behaviour }\end{array}$ & $\begin{array}{l}\text { Number of times action/behaviour has occurred } \\
\text { within a year. }\end{array}$ \\
\hline 8 & $\begin{array}{c}\text { Revisit } \\
\text { Intention } \\
\end{array}$ & $\begin{array}{l}\text { Willingness to revisit destination or other } \\
\text { similar destinations. }\end{array}$ \\
\hline 9 & Skill & $\begin{array}{l}\begin{array}{l}\text { The ability to undertake certain/task } \\
\text { proficiently. }\end{array} \\
\end{array}$ \\
\hline 10 & Challenge & $\begin{array}{l}\text { Level of difficulty faced in undertaking an } \\
\text { action. }\end{array}$ \\
\hline 11 & Flow & $\begin{array}{l}\text { State experienced by an individual where there } \\
\text { is a loss of the sense of time and reflective self- } \\
\text { consciousness in undertaking a task/action. }\end{array}$ \\
\hline 12 & Involvement & $\begin{array}{l}\text { Willingness to commit and show effort in } \\
\text { undertaking a specific action/task. }\end{array}$ \\
\hline 13 & $\begin{array}{l}\text { Relational } \\
\text { Experience }\end{array}$ & $\begin{array}{l}\text { Sense of belonging of an individual to a social } \\
\text { group. }\end{array}$ \\
\hline 14 & $\begin{array}{l}\text { Perceived } \\
\text { Authenticity }\end{array}$ & $\begin{array}{l}\text { Subjective evaluation on the genuineness of } \\
\text { subject matter. }\end{array}$ \\
\hline
\end{tabular}

\section{RESULTS AND ANALYSIS}

In the analysis of themes of customer experience on escape room perceptions, 14 themes appear to be prominently mentioned. Among the said themes, eleven matched MGB framework. Another six were newly discovered elements and they are listed out as skill, challenge, flow, involvement, relational experience and perceived authenticity.

\section{A. Attitude}

In terms of attitude, sample subjects who are new in the 
gameplay and those who have played before, have different notions in their attitude which comprises the categories of belief and affection.

The first-time players (FPs) have a pre-conceived expectation in the game set of escape rooms. This is largely attributed to lack of understanding on what Escape Room is about. Based on the fragmented information gathered from the player's sources of information, they form a preliminary image in their mind from drawing attributes which are relatable instances related to their lives, which in turn, shape their expectations.

Sample subject no. 9 reported that her first conception of escape room gameplay was derived from her conversations with her sons. To her surprise it was not as expected, and it took her quite a while to process the mechanics of the gameplay. Her assumption that escape rooms were for children changed instantly. She classified it as a valuable and interesting experience. Sample subject no. 1, on the other hand, had never heard escape rooms. His thoughts were either it was an arcade game or a funfair sort of stall game as he saw the ad of a photo where a group of people posed in front of a backdrop with their achievements. He was just as amazed as sample subject no. 9 and there was no comparison to what Escape Room is akin to. Table V depicted sample responses to display attitude.

Further questioning resulted to FPs admitting having positive emotions are it in pre-purchase, during or post. In pre-purchase, marketing collateral of the escape room activated their interest and curiosity aroused their desires to embark on this escape room challenges. During purchasing phase, they have good interaction with other contenders either their friends, families, relatives or even as a standalone in a mixed group. In the post purchase, there arises excitement and discussion and often was their post-mortem of their gameplay. For instance, sample subject no. 15, saw a marketing video and she believed she would enjoy the challenge as much as the people in the advertisement. Sample subject no. 12, on the other hand was scared to be involved in the gameplay. Her attitude changed after she conversed with one of the players

Conversely, players who had played before; repeated players (RPs) had a tendency to demonstrate a more goaloriented attitude towards their same gameplay. As said by sample subject no. 19, he was most concerned about the level of difficulty. His rationale was always be prepared and the advice was to start off with the easier escape plan before attempting the harder ones. To him, the games set were not IQ based and sometimes it required a bit of luck. He took the initiative to play the same room game again with a mind to beat the clock to escape in a more organized manner.

In conclusion, FPs and those who have played are positive towards the escape room games. However, RPs have strong goal orientation and they maintain their positive attitude, even though they have gone through the gameplay before. The researcher finds this in contrary to the findings of Nicholson (2015), who stated that RPs lose interest gradually when they played the game again.

\section{B. Subjective Norm}

Subjectivity of norm affects both the FPs and RPs when it comes to the games played in the escape rooms. The categories of influences are peer recommendation and peer pressure.

Most responses of FP sample subjects are dependent on subjectivity of the norm. They have little knowledge of the gameplay in the escape rooms, so they are greatly influenced from the recommendations of people (friends, families, relatives or players) in picking the varieties of rooms available and also their invitation to play a certain escape room.

Sample subject no. 5, acknowledged that is a true insight as she personally played the challenge recommended by her peers. Same goes to sample subjects no. 13 and 15 while sample subjects no. 6 and 17 were influenced by players who have just completed the challenges.

On the other hand, from RPs' perspectives, they are also inclined towards trying rooms or games recommended by people (friends, families, relatives or players) because it is deemed a good gameplay and perhaps a must not missed. They want to be part of the crowd, so to speak and experience the challenges similar to their peers. They were pressured to play and excel better than their peers.

Sample subject number 10 had those concepts when her friends played a game which she did not and she would definitely proceed to play the recommended room the next weekend and prayed she would be better so that she stood out among her friends.

\section{Positive Anticipated Emotions}

In [15] found positive anticipated emotions listed as fun, exciting and satisfying were the most cited emotions in his studies.

FPs in this study, have displayed positive anticipate emotions in the pre purchase, during purchase and postpurchase stages. As mentioned earlier, FPs attained these positive emotions from people and promotional videos in the early stage; pre-purchase. During purchase, is the phase where they would start to judge the gameplay and if it lived up to their expectations the positive flow of emotions such fun, exciting and satisfying are common expressions heard. Nevertheless, those were not the only words sample FPs uttered. Due to the nature of escape rooms that literally tap into social and physical desires of these said FPs while providing intellectual stimulation and thrill, positive anticipate emotions words have extended to phrases like fabulously delightful, filled with happiness, extremely motivated and ecstatically exciting. Sample subjects no. 6 and 17 felt the gameplay was ecstatically exciting and a great adventure.

As for our RPs, they feel the wild excitement especially if they are introducing or playing the gameplay with the newbies. They feel very much in control and confident and their level of satisfaction is high especially if the newbies proclaimed that the gameplay is fantastic.

Sample subject no. 4 admitted that she was truly happy when her colleague praised her for finding such an exciting pastime. The researcher could see her face beaming when she made her response. 


\section{Negative Anticipated Emotions}

Negative anticipated emotions are not necessarily bad for FPs, RPs and the business operators of this nature. In fact, it leads to positive after-effects.

Some sample subjects FPs have negative anticipated emotions even before the gameplay started. They were skeptical of this new gaming experience which they were about to embark on. They were worried that what they paid for would not match their expectations. In addition, they felt a lot of uncertainty when the rules of the game plan were being explained. They also felt a bit stress as they might not complete the quest in time.

Sample subject no. 11, experienced this emotional rollercoaster during the briefing session by the gamemaster as she did not know what to expect and how she would fare in the gameplay.

RPs have less negative anticipated emotions as they have played the game before or have played other escape room games before. There were no negative anticipated emotions during the explanation of rules as they were all ready to escape the room. The only negative anticipated emotions displayed would be the inability to complete the game or if they performed worse than the first time.

Sample subject no. 19 agreed that he felt horrible since he did not do better than the last challenge. He said he felt upset but would choose to try again.

Hence, negative anticipated emotions are foreseen to wear off eventually and more than often it is being replaced by positive anticipated emotions. Even, if there exists stress, it is considered fine as in [63], a pair of sociologists claim, "When we're just the right level of aroused — which can happen from fear, stress, anxiety, fun, et cetera - we perform better."

\section{E. Perceived Controlled Behaviour}

Self-efficacy is the perceived controlled behaviour which appeared to be the second most cited theme among our sample subjects (FRs and RPs) in this study. In [64] defined self-efficacy as the belief of one's own abilities, explicitly the ability to meet challenges and accomplish tasks with success.

Sample subjects FPs exhibit relatively low self-efficacy as they have very little understanding on the gameplay escape rooms have to offer. Their doubts due to this low self-efficacy status often made them opt for the easiest achievable room which might not be par with their true ability.

Sample subject no. 7 lacked confidence when she signed up for the challenge. She was not sure she had the ability to could finish the game, so she chose the room that had less stars (i.e. lower difficulty). Similarly, sample subject no. 3 picked the room with the highest completion rate citing a lack of confidence and experience as the motivation for her choice.

FPs are also known to have low self-efficacy as they have the tendencies to rely heavily on either the game masters or teammates during purchase or game stage. Sample subject no. 9 felt blessed as she has the support of her teammates and game master to aid her escape the room.

If all members are FRs, they are dependent on Game Masters, as they provide valuable tips occasionally to find clues or solve the puzzles. Sample subject no. 8 was thankful to the game master. He and his wife were first timers, and he was very sure that if they were left alone, they would have been stuck until the time was up.

Normally, RPs have higher self-efficacy than FRs as they have some experience in the escape rooms before. They are generally more inclined to remain independent in their gameplay. This is mirrored by sample subject no. 10. She said she did not ask any help from the game master because she felt it was cheating and in real life there would be no cheat code.

\section{F. Desire}

Desire in context with customer experience from sample subjects of the escape room refers to personal motivation wishes of outcomes expected of the gameplay. In [65] believed that desire is what moved people, and, in that move, it offers them two values; life direction and meaning. According to him, this said meaning is not cosmical but more confined towards narrative. Hence, if there is a desire to go for the challenge for the escape room, it is due to certain reasons formed from the desire that motivate one to play the gameplay for both FRs and RPs.

FPs often comes with a desire to do better. Somehow, they are often not satisfied with their first time around performance. Other desires are like being able to solve the puzzles and clues. Whatever, the desires are such reactions are not surprising. The core problem arises from their low self-efficacy. They underestimate their own abilities because they do not know what to expect.

Sample subject no. 3 wished that she could do better in the next game. On the other hand, sample subject no. 7 hoped to solve the puzzles quicker to advance to the next level as she became more familiarized with the gameplay.

RPs have different desires compared to the FRs. Firstly, their level of self-efficacy is higher and they have the one desire to beat the clock in the gameplay and if possible with any aid. Sample subject no. 10 is the perfect example. She repeatedly said it was cheating and to her there is no glory either if she escapes the room with the game master's tips.

\section{G. Frequency of Past Behaviour}

In this study, frequency of past behaviour was capped at how many rooms and how many establishments the RPs have visited in a year.

FPs are all first timers, so they refrained from answering this section. The frequency of past behaviour for the sample subjects RPs were categorized in Table IV.

Table- V: Frequency of past behavior

\begin{tabular}{|c|c|c|}
\hline $\begin{array}{c}\text { Sample } \\
\text { Subject }\end{array}$ & $\begin{array}{c}\text { Number of } \\
\text { Establishments }\end{array}$ & $\begin{array}{c}\text { Number of Games } \\
\text { Played }\end{array}$ \\
\hline 11,4 & 1 & 1 \\
\hline 15 & 1 & $>1$ \\
\hline
\end{tabular}

\section{H. Revisit Intention}

To all escape rooms establishments, this is the most essential part of the study, as revisit intention of customers 
displays a huge impact of the success or failure of this sort of entertainment entity. Its significance relevance is an important behavioral reaction as it reveals its antecedents. In layman terms, the more positive the feedback is, the brighter it is for the future of this unique sort of entertainment.

In this study, the reviews were particularly positive for both the FPs and RPs. This is one aspect where the similarity level achieved $100 \%$. They all have plans to participate in more gameplays of escape rooms.

Majority of players convinced the researcher that they would visit this escape room again with their families, friends or peers. Some of the first-time players such as respondent no. 11 and no. 12 intended to visit another branch of this escape room establishment while others alike respondent no. 17 and no. 19 intend to replay the same room on their next visit and one FRs was so keen that he actually booked for the next visit.

\section{Skill}

Skill is one of the six themes (skill, challenge, flow, involvement, relational experience and perceived authenticity) identified by the researcher as customer experience which is not inscribed in the MGB framework. In [66] proclaimed that skills are natural talents and abilities developed to perform a task or job. In this case, it refers to two contexts; time management and problem solving.

Time management of FPs is often found to be poorer than RPs as they are not too familiar with escape rooms. Normally, they are not so organized as it is the first teamwork with their families, friends or peers. Sample subject no. 20 thought he was pretty lost. He was running

If there are FRs who have always been working together closely then there may exist collaboration as there are possibility to leverage each other's' strengths or weaknesses. Sample subject no. 5 went in with colleagues who worked in projects together in their workplace. Hence, they were able to have a plan in their gameplay.

\section{J. Challenge}

Escape Rooms itself is a challenge. It is a fun, interactive game which involves quick thinking, communication and teamwork. All players who signed up for the gameplay are considered ready to accept the challenge. However, it is important to ascertain the level of difficulty of the challenge to ensure people enjoy a good game.

To sample subject FPs diagnosed as having low selfefficacy, they have probably opted for a room with a high chance of escape. If puzzles and clues are found too simple or too hard, either way FPs will lose interest. Hence, in escape rooms, there is always a mixture of simple, mediocre and hard tasks to ensure FPs feel the challenge and strive to complete the escape. Sample subject no. 12 said, the gameplay forced her to solve multiple puzzles which challenged her to perform to the best of her abilities. She revealed that the level of difficulty was just right for her to enjoy the experience.

Secondly, for FPs, it is a challenge for them to work as a team to escape. Hence, as sample subject no. 14 professed, the gameplay was a test to assess his ability to work together with others to produce results. here and there looking for clues with no strategy in mind.

As for sample subject RPs, their thoughts of the gameplay differ. They know what to expect and the difficulty level are not their main concern. Sample subject no. 10 thought the gameplay challenges her to think out of the box and sample subject no. 19 expressed it tested his problem-solving skills.

\section{K. Flow}

Regardless what activities are conducted in whatever class, gender, age, race or culture, the experience of flow occurs [67]. Flow is universal to all although the capacity of experiencing flow differs from person to person.

In this study, flow was assessed to check balance the captivity of the gameplays towards our sample subjects. Both FPs and RPs were highly captivated. Their responses were mostly regarding losing conscious such as to their concentration while solving the puzzle or clues, time and even their surroundings.

\section{Involvement}

When the experience of flow is attained, involvement is, of course, at its peak. Involvement has 4 stages according to the consumer involvement theory (CIT) as shown in Fig 1.

In this study, it was found applicable to sample subject FPs only. Their involvement is high even at pre-purchase stage. Before attempting participation, sample subject no. 13 confessed that he was frantically searching for all information on escape rooms. He even watched videos on YouTube.

During the gameplay, if it was a group of FPs then they were relatively dependent on the game master to figure out clues, but a group of FPs and RPs entails FPs to become dependent on RPs to make the move. They would seek approval from the RPs as they rationally believed RPs could help them escape faster as admitted by sample subject no. 5 .

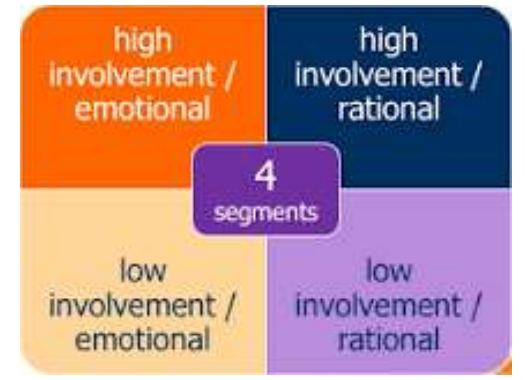

Fig. 1.Consumer involvement theory

\section{Relational Experience}

This theme; relational experience is strongly exhibited in those who played the same room again. Hence, it was not applicable to FPs. The reason as to why attempts were made more than once alike sample subject no 4 , who played five times was her desire to achieve goals such as completing the game on time or beating the clock and stand out to be high achievers.

\section{N. Perceived Authenticity}

In [68] said that perceived authenticity is, in fact, a construct of negotiation and interpretation of the consumer, 
himself based on his own experiences and its interpretation is within the social context. In this study, perceived authenticity mirrors perceptions of sample subjects of FPs and RPs towards the novelty of the Escape Room as a gaming concept.

This was clearly observed in sample subject FPs as most of them were amazed at its novelty as an entertainment activity. Sample subject no. 3 acknowledged the idea was refreshing. Never for life would she thought escaping from prison was a fun task.

RPs' perceived authenticity was more to toward the accuracy of room depicting the scenario/ situation. Sample subject no. 10 was astounded with the props in M\&M Big escape which had the Night of the Museum vibe. To her, "the deco looked so real and legit".

\section{DISCUSSION}

Based on the results attained from this study, the core findings highlighted the perspectives of Escape Room customers, as having the ability to retain a great impact of customer revisit intention. This insight complements the broad concept proposed by [15]. The analysis conducted unveiled that customer experience of FPs and RPs differ in the general sense except for certain themes. However, the most prominent of it all, is the said return intention mentioned earlier. This determinant is specifically one of the Directed Behaviour.

The researcher also found out that customer experience of escape rooms is affected widely by the subjectivity of the norm. This is not difficult to digest especially when it involved FPs who have little knowledge on escape room real life gaming. They seek assurance from word of mouths i.e. from their peers, friends, families, relatives and other players on the spot.

A closer examination revealed that the finding is similar to some previous studies where subjective norm is a legitimate influence on the desire of visitors' visitation destination [47], [69]. The said researchers discovered the perceptions of visitors played a vital role in attracting other visitors to the festival held each year in the township. With the advent of technology such references are further tweeted in social media networks like travel blogs, Twitter and Facebook. If customers' reviews, ratings or recommendations are excellent, it is most likely the business will flourish by leaps and bounds.

Another prominent theme of discussion is perceived control behaviour i.e. pertaining to the self-efficacy of its consumers towards achieving their desired goals. Low selfefficacy of FPs often detained them from taking risks; purchasing high difficulty games due to the fact that they might not gain maximum value for their paid experience. Normally, FPs have a limitation to the degree of risks they are willingly to embark on. This co-relates to previous studies on customer experience related to technology use intention [70], [71]. achiever of experience at an optimal state. It also indicates the experience of flow as the recipe of captivity of consumers' interest by large. The balancing of skill and challenge are vital as well to buy in customers. most important elements inscribed in the Model of Goal-

Lastly, this study demonstrates immersion as the key

\section{CONCLUSION}

Potentially, this study has exemplified the themes (elements) of customer experience in which eleven are paired well with the MGB framework. In addition, it has identified another six vital ones and they are skill, challenge, flow, involvement, relational experience and perceived authenticity through the study of two escape room establishments in Malaysia.

The study is crucial, as this is a new and unique form of entertainment business that sells nothing but experiences. Therefore, sustainability can only be determined through a thorough research on customer experience so that operators will be able to satisfy the needs of their customers. This is vital to gain frequent customers' visits and attain profits which are the main point of operating a business. Besides, it is a known fact that customer experience is contextual, subjective and perceptual. Hence, it needs to be constantly assessed and monitored to be up to date with recent revolutions in customer appetites.

In conclusion, the findings have captured the dynamic and diverse nature of the customer experience from FPs and RPs of the escape rooms by employing a sequential incident technique to attain their insightful descriptions. These are exclusive to business operators not only to identify their shortcomings, but to further improve their products (escape rooms) accordingly. This is to ensure their customers fully enjoy their experience and are willing to come back for more It also helps them to highlight different themes (elements) between FPs and RPs.

\section{REFERENCES}

1. K. Heinonen, C. Campbell, and S. L. Ferguson, "Strategies for creating value through individual and collective customer experiences," Business Horizons, 62(1), 2019, pp. 95-104.

2. J. Kandampully, T. Zhang, and E. Jaakkola, "Customer experience management in hospitality: A literature synthesis, new understanding and research agenda," International Journal of Contemporary Hospitality Management, 30(1), 2018, pp. 21-56.

3. J. E. Collier, D. C. Barnes, A. K. Abney, and M. J. Pelletier, "Idiosyncratic service experiences: When customers desire the extraordinary in a service encounter," Journal of Business Research, 84, 2018, pp 150-161.

4. A. Følstad and K. Kvale, "Customer journeys: A systematic literature review," Journal of Service Theory and Practice, 28(2), 2018, pp. 196-227.

5. R. Jain, J. Aagja, and S. Bagdare, "Customer experienceA review and research agenda," Journal of Service Theory and Practice, 27(3), 2017, pp. 642-662.

6. R. A. Nasution, A. Y. Sembada, L. Miliani, N. D. Resti, and D. A. Prawono, "The customer experience framework as baseline for strategy and implementation in services marketing," Procedia-Social and Behavioral Sciences, 148, 2014, pp. 254-261.

7. L. E. Dubois and C. Gibbs, "Video game-induced tourism: A new frontier for destination marketers," Tourism Review, 73(2), 2018, pp. 186-198.

8. J. Novy and C. Colomb, "Urban tourism as a source of contention and social mobilisations: A critical review,"

Published By:

Blue Eyes Intelligence Engineering 
Tourism Planning and Development, 16(4), 2019, pp. 358-375

9. S. Nicholson. (2015). Peeking behind the locked door: A survey of escape room facilities. [Online]. Available: http://scottnicholson. com/pubs/erfacwhite. pdf.

10. K. A. Bartlett and J. L. Anderson, "Gaming to learn: Bringing escape rooms to the classroom," in Handbook of Research on Innovative Digital Practices to Engage Learners, P. H. Bull and J. Keengwe, Eds. London: IGI Global, 2019, pp. 1-27.

11. PlayExitGames. (2019). Escape Rooms by country. [Online]. Available: https://www.playexitgames.com/search-by-country/.

12. S. French and J. M. Shaw. (2015). The unbelievably lucrative business of escape rooms. [Online]. Available: https://www.marketwatch.com/story/the-weird-newworld-of-escape-room-businesses-2015-07-20.

13. Z. Zaki, OWG buys $60 \%$ stake in Escape Room. 2015.

14. Z. Stone. (2017). Escape the startup is a terrifying twist on silicon valley culture. [Online]. Available: https://www.forbes.com/sites/zarastone/2017/01/17/escap e-the-startup-is-a-terrifying-twist-on-silicon-valleyculture/.

15. T. Kolar, "Conceptualising tourist experiences with new attractions: The case of escape rooms," International Journal of Contemporary Hospitality Management, 29(5), 2017, pp. 1322-1339.

16. M. B. Holbrook and E. C. Hirschman, "The experiential aspects of consumption: Consumer fantasies, feelings, and fun," Journal of Consumer Research, 9(2), 1982, pp. $132-140$

17. M. Rokeach, "The consumer's changing image," Society, 1(5), 1964, pp. 7-10.

18. A. Mehrabian and J. A. Russell, An Approach to Environmental Psychology. Cambridge: MIT Press, 1974. Marketing, 56(2), 1992, pp. 57-71.

20. B. Schmitt, "Experiential marketing," Journal of Marketing Management, 15(1-3), 1999, pp. 53-67.

21. M. Csikszentmihalyi and M. Csikzentmihaly, Flow: The Psychology of Optimal Experience. New York: Harper Perennial, 1991.

22. W. C. Compton and E. Hoffman, Positive psychology: Sage Publications, 2019.

23. E. J. Arnould and L. L. Price, "River magic: Extraordinary experience and the extended service encounter," Journal of Consumer Research, 20(1), 1993 , pp. $24-45$.

24. B. J. Pine, J. Pine, and J. H. Gilmore, The Experience Economy: Work is Theatre and Every Business A Stage.

25. A. Carù and B. Cova, "Revisiting consumption experience: A more humble but complete view of the concept," Marketing Theory, 3(2), 2003, pp. 267-286.

26. S. L. Vargo and R. F. Lusch, "Service-dominant logic: Continuing the evolution," Journal of the Academy of Marketing Science, 36(1), 2008, pp. 1-10.

27. L. L. Berry, L. P. Carbone, and S. H. Haeckel, "Managing the total customer experience," MIT Sloan Management Review, 43(3), 2002, pp. 85-89.

28. P. C. Verhoef, K. N. Lemon, A. Parasuraman, A. Roggeveen, M. Tsiros, and L. A. Schlesinger, "Customer experience creation: Determinants, dynamics and management strategies," Journal of Retailing, 85(1), 2009, pp. 31-41.

29. K. N. Lemon and P. C. Verhoef, "Understanding customer experience throughout the customer journey," Journal of Marketing, 80(6), 2016, pp. 69-96.
19. M. J. Bitner, "Servicescapes: The impact of physical surroundings on customers and employees," Journal of The science of happiness and flourishing. California: Massachusetts: Harvard Business Press, 1999.

30. C. Gentile, N. Spiller, and G. Noci, "How to sustain the customer experience: An overview of experience components that co-create value with the customer," European Management Journal, 25(5), 2007, pp. 395410

31. C. K. Prahalad and V. Ramaswamy, "Co-creation experiences: The next practice in value creation," Journal of Interactive Marketing, 18(3), 2004, pp. 5-14.

32. A. Scherer, N. V. Wünderlich, and F. V. Wangenheim, "The value of self-service: Long-term effects of technology-based self-service usage on customer retention," MIS Quarterly, 39(1), 2015, pp. 177-200.

33. A. Bleier, C. M. Harmeling, and R. W. Palmatier, "Creating effective online customer experiences," Journal of Marketing, 83(2), 2019, pp. 98-119.

34. Z. W. Y. Lee, T. K. H. Chan, A. Y. L. Chong, and D. R Thadani, "Customer engagement through omnichannel retailing: The effects of channel integration quality," Industrial Marketing Management, 77, 2019, pp. 90-101.

35. V. Grover, R. H. L. Chiang, T. P. Liang, and D. Zhang, "Creating strategic business value from big data analytics: A research framework," Journal of Management Information Systems, 35(2), 2018, pp. 388423.

36. M. Perugini and R. P. Bagozzi, "The role of desires and anticipated emotions in goal-directed behaviours: Broadening and deepening the theory of planned behaviour," British Journal of Social Psychology, 40(1), 2001, pp. 79-98.

37. M. Perugini and M. Conner, "Predicting and understanding behavioral volitions: The interplay between goals and behaviors," European Journal of Social Psychology, 30(5), 2000, pp. 705-731.

38. B. Meng and K. Choi, "The role of authenticity in forming slow tourists' intentions: Developing an extended model of goal-directed behavior," Tourism Management, 57, 2016, pp. 397-410.

39. Y. H. Shin, H. Kim, and K. Severt, "Antecedents of consumers' intention to visit food trucks," Journal of Foodservice Business Research, 21(3), 2018, pp. 239256.

40. W. Chiu and H. Choi, "Consumers' goal-directed behavior of purchasing sportswear products online: A case study of Chinese consumers," Sport, Business and Management: An International Journal, 8(2), 2018, pp. 118-133.

41. Y. Li, N. M. Ashkanasy, and D. Ahlstrom, "The rationality of emotions: A hybrid process model of decision-making under uncertainty," Asia Pacific Journal of Management, 31(1), 2014, pp. 293-308.

42. E. Tanovic, L. Pruessner, and J. Joormann, "Attention and anticipation in response to varying levels of uncertain threat: An ERP study," Cognitive, Affective, and Behavioral Neuroscience, 18(6), 2018, pp. 12071220 .

43. Tong, E., Passion, identity, and the model of goaldirected behaviour in a classical music context. Phd thesis, Victoria: RMIT University, 2016.

44. K. D. Ersche, C. M. Gillan, P. S. Jones, G. B. Williams, L. H. E. Ward, M. Luijten, S. de Wit, B. J. Sahakian, E. T. Bullmore, and T. W. Robbins, "Carrots and sticks fail to change behavior in cocaine addiction," Science, 352(6292), 2016, pp. 1468-1471.

45. S. Esumi, H. Sagara, A. Nakamoto, Y. Kawasaki, Y. Gomita, and T. Sendo, "Effect of GBR12909 on affective behavior: Distinguishing motivational behavior from 
antidepressant-like and addiction-like behavior using the runway model of intracranial self-stimulation," Behavioural Brain Research, 243, 2013, pp. 313-321.

46. A. Gabbiadini, F. Cristini, L. Scacchi, and M. G. Monaci, "Testing the model of goal-directed behavior for predicting binge drinking among young people," Substance Use and Misuse, 52(4), 2017, pp. 493-506.

47. H. J. Song, G. J. You, Y. Reisinger, C. K. Lee, and S. K. Lee, "Behavioral intention of visitors to an oriental medicine festival: An extended model of goal directed behavior," Tourism Management, 42, 2014, pp. 101-113.

48. E. Park, S. Lee, and D. J. Peters, "Iowa wetlands outdoor recreation visitors' decision-making process: An extended model of goal-directed behavior," Journal of Outdoor Recreation and Tourism, 17, 2017, pp. 64-76.

49. L. Becker, "Methodological proposals for the study of consumer experience," Qualitative Market Research: An International Journal, 21(4), 2018, pp. 465-490.

50. J. Pöppel, J. Finsterwalder, and R. A. Laycock, "Developing a film-based service experience blueprinting technique," Journal of Business Research, 85, 2018, pp. 459-466.

51. P. Randhawa, M. Kim, and R. F. Cichy, "Service innovations: What the managers believe and what the customers say," Journal of Hospitality Marketing \& Management, 26(2), 2017, pp. 186-206.

52. I. S. Wahyuni-Td and Y. Fernando, "Growing pains the low cost carrier sector in Indonesia: Internal service quality using a critical incident technique," Safety Science, 87, 2016, pp. 214-223.

53. M. Hubermanand M. B. Miles, The Qualitative Researcher's Companion. California: Sage Publications, 2002.

54. M. Q. Patton, Qualitative Research and Evaluation Methods. California: Sage Publications, 2002.

55. B. Staussand B. Weinlich, "Process-oriented measurement of service quality: Applying the sequential incident technique," European Journal of Marketing, 31(1), 1997, pp. 33-55.

56. J. C. Flanagan, "The critical incident technique," Psychological Bulletin, 51(4), 1954, pp. 327-358.

57. A. Decker and H. Meissner, "The Sequential Incident Technique for Innovations (SITI) - A tool for generating improvements and ideas in service processes," in Service Quality and Management, P. Kunst, J. Lemmink and B. Stauss, Eds. Deutscher Universitätsverlag, Wiesbaden, 1999, pp. 187-226.

58. D. W. Turner III, "Qualitative interview design: A practical guide for novice investigators," The Qualitative Report, 15(3), 2010, pp. 754-760.

59. D. S. McNamara and J. Magliano, "Toward a comprehensive model of comprehension," Psychology of Learning and Motivation, 51, 2009, pp. 297-384.

60. H. Kallio, A. M. Pietilä, M. Johnson, and M. Kangasniemi, "Systematic methodological review: Developing a framework for a qualitative semi-structured interview guide," Journal of Advanced Nursing, 72(12), 2016, pp. 2954-2965.

61. K. M. Eisenhardt and M. E. Graebner, "Theory building from cases: Opportunities and challenges," Academy of Management Journal, 50(1), 2007, pp. 25-32.

62. J. Maxwell, "Understanding and validity in qualitative research," Harvard Educational Review, 62(3), 1992, pp. 279-301.

63. S. P., Kerr, W. R. Kerr, and T. Xu, "Personality traits of entrepreneurs: A review of recent literature," Foundations and Trends ${ }^{\circledR}$ in Entrepreneurship, 14(3), 2018, pp. 279-356.

64. M. Akhtar, Positive Psychology for Overcoming Depression: Self-Help Strategies for Happiness, Inner
Strength and Well-Being. London: Watkins Media Limited, 2012.

65. C. R. Burton, E. Fargher, C. Plumpton, G. W. Roberts, H. Owen, and E. Roberts, "Investigating preferences for support with life after stroke: A discrete choice experiment," BMC Health Services Research, 14(1), 2014, pp. 1-13.

66. R. C. Yorkey, Study Skills. New York: Prentice-Hall, 1970.

67. M. Oppland, Mihaly Csikszentmihalyi: All about flow \& positive psychology. Positive Psychology Program, 2016.

68. L. L. M. Turunen, Interpretations of luxury: Exploring the consumer perspective. Cham: Palgrave Macmillan, 2017.

69. M. Chang, J. H. Kim, and D. Kim, "The effect of food tourism behavior on food festival visitor's revisit intention," Sustainability, 10(10), 2018, pp. 1-15.

70. A. I. Yusta, C. O. Pascual, and E. R. Lara, "Attitudes toward mobile advertising among users versus non-users of the mobile Internet," Telematics and Informatics, 32(2), 2015, pp. 355-366.

71. S. Rose, M. Clark, P. Samouel, and N. Hair, "Online customer experience in e-retailing: An empirical model of antecedents and outcomes," Journal of Retailing, 88(2), 2012, pp. 308-322.

\section{AUTHORS PROFILE}

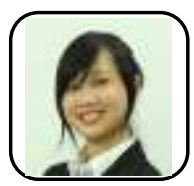

Lim Qian Pink is currently pursuing PHD in service management at Universiti Malaysia Pahang (UMP). She graduated with an MBA degree from UMP in 2014. She is also an analyst at the Central Bank of Malaysia overseeing the development of Islamic banking and takaful industry in Malaysia. Her areas of specialisation are customer experience, Islamic finance, trade finance and halal sector

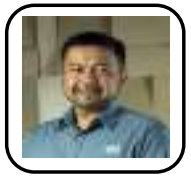

Associate Professor Dr. Ridzuan Mohd is the founding Dean of Faculty of Industrial Management (FIM), Universiti Malaysia Pahang (Malaysia) (UMP). He is current the Chief Operating Officer of UMP. He is an expert in management accounting, management control system, Halal supply chain and working capital management. He has great interest on Blockchain Technology and currently leading various projects on the adoption of Blockchain technology on supply chain, mobile wallet and anti-forgery apps. Ridzuan has been appointed as the new Chairman of Peer Review Committee of ABEST21 based in Japan (2017-2019). He obtained his Bachelor of Science in Finance (majoring in corporate finance and investment) from Southern Illinois University at Carbondale, USA Master of Business Administration from Universiti Utara Malaysia, and a $\mathrm{PhD}$ in Accounting from Lincoln University, New Zealand. Under his leadership, FIM obtained an international accreditation from ABEST21. He also created a new FIM Governance and Integrity Centre (FGIC) and FIM Learning Factory. Furthermore, he established several new collaborations with related international and domestic institutions.

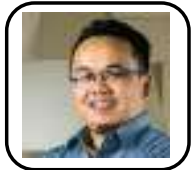

Dr. Gusman Nawanir is currently a senior lecturer at Faculty of Industrial Management, Universiti Malaysia Pahang. He received his $\mathrm{PhD}$ (operations management) in 2016 and conferred his MSc (operations management) in 2011 from the School of Technology Management and Logistics at the Universiti Utara Malaysia. He attained his bachelor degree (industrial engineering) in 2003 from the Engineering Faculty, University of Andalas, Indonesia. His primary research and publication area includes lean manufacturing, manufacturing flexibility, quality management, logistics and supply chain management, and performance measurement. His teaching interests are in the area of production and operations management, quality management, research methodology, and statistical data analysis. 
Dr. Chiam Kee Swan is currently a senior lecturer at the Centre of Modern Languages, Universiti Malaysia Pahang. She received her $\mathrm{PhD}$ (TESL) from Universiti Putra Malaysia in 2015. Her specializations include pedagogy, learning styles, reading comprehension, drama, public speaking and various other forms of modern art and literature. 